Pacific Journal of Mathematics

MUTUALLY APOSYNDETIC PRODUCTS OF CHAINABLE 


\title{
MUTUALLY APOSYNDETIC PRODUCTS OF CHAINABLE CONTINUA
}

\author{
LELAND E. ROGERS
}

\begin{abstract}
In this paper it is proved that the Cartesian product of two compact metric chainable continua is mutually aposyndetic if and only if each of the two factors is an arc. Also some relationships are shown between indecomposability and a strong form of non-mutual aposyndesis.
\end{abstract}

1. In [5], C. L. Hagopian developed the notion of mutual aposyndesis, a "Hausdorff" version of F. B. Jones' aposyndesis [6]. Mutual aposyndesis is stronger than aposyndesis but in general weaker than local connectedness. However, Theorem 1 of this paper shows that mutual aposyndesis and local connectedness are equivalent in a certain case.

Jones showed [7] that if a continuum is not aposyndetic at any point with respect to any other point, then it is indecomposable. A similar notion for mutual aposyndesis, called strict nonmutual aposyndesis by Hagopian, is closely related to indecomposability [5]. The author extends mutual aposyndesis to the notion of $n$-mutual aposyndesis and shows a relationship between strict non- $n$-mutual aposyndesis and $n$-indecomposability.

2. Definitions and notation. All spaces considered in this paper are compact and metric. A continuum is a nondegenerate closed connected set. The continuum $M$ is aposyndetic at a point $x$ with respect to a point $y$ if there is a subcontinuum in $M-y$ containing $x$ in its interior [6]. We shall say that $M$ is semi-aposyndetic at $\{x, y\}$ if $M$ is aposyndetic either at $x$ with respect to $y$ or at $y$ with respect to $x$. If $n \geqq 2$ and $A$ is an $n$-point set, we say that $M$ is $n$-mutually aposyndetic at $A$ if there are $n$ disjoint subcontinua of $M$, each containing a point of $A$ in its interior. If $M$ is $n$-mutually aposyndetic at each n-point set, then $M$ is said to be n-mutually aposyndetic. If $M$ is $n$-mutually aposyndetic at no $n$-point set, then $M$ is strictly non-n-mutually aposyndetic. For $n=2$ we obtain the notions of mutual aposyndesis and strict nonmutual aposyndesis [5]. For each point $x$ in $M, L_{x}$ denotes the set of all points $y$ such that $M$ is not aposyndetic at $y$ with respect to $x$, and $K_{x}$ denotes the set of all points $y$ such that $M$ is not aposyndetic at $x$ with respect to $y$. If $p, q$, and $r$ are distinct points of $M, p$ cuts $q$ from $r$ if each continuum in $M$ containing both $q$ and $r$ also contains $p$. ("Cut weakly" is sometimes used; this is not the same as to "separate".) 
A chain is a finite collection $\left\{E_{1}, \cdots, E_{m}\right\}$ of open sets such that $E_{i} \cap E_{j} \neq \varnothing$ if and only if $|i-j| \leqq 1$. The elements of a chain are called links. For $\varepsilon>0$ an $\varepsilon$-chain is a chain in which each link has diameter less than $\varepsilon$. A continuum is chainable if for each $\varepsilon>0$, it can be covered by an $\varepsilon$-chain. An $\varepsilon$-map on a continuum $M$ will denote a continuous function $f$ from $M$ onto $[0,1]$ such that for each $r \in[0,1], \operatorname{diam} f^{-1}(r)<\varepsilon$. A chainable continuum $M$ is also characterized by the property that for each $\varepsilon>0$, there is an $\varepsilon$-map on $M$. An endpoint of a chainable continuum is a point $p$ such that for each $\varepsilon>0, p$ is in the first link of some $\varepsilon$-chain covering $M$.

A continuum irreducible between two points is of type $A$ [10] if there is a monotone upper semi-continuous decomposition of $M$ onto an arc. A continuum $M$ is of type $A^{\prime}$ [10] if $M$ is of type $A$ and has a decomposition in which no element has interior.

A subcontinuum $T$ of the continuum $M$ is terminal [4] if for each pair of subcontinua $A, B$ which intersect $T$, either $A \subset B \cup T$ or $B \subset A \cup T$. If $p$ is a point of an indecomposable subcontinuum $K$ of $M, p$ is an inaccessible point of $K$ [4] if for each subcontinuum $R$ of $M$ which contains $p$, either $R \subset K$ or $K \subset R$.

REMARK. If $\varepsilon>0$ and $T$ is a terminal subcontinuum of a chainable continuum $M$, then there is an $\varepsilon$-map $f$ on $M$ such that $f(T)$ is an initial segment of $[0,1]$. (This can be shown using Lemma 1 of [4].)

A continuum $M$ is the finished sum [9] of subcontinua $A_{1}, \cdots, A_{k}$ if $M=\bigcup A_{i}$ and for each $j, A_{j} \not \subset \bigcup_{i \neq j} A_{i}$. The continuum $M$ is $n$ indecomposable [9;2] if $M$ is the finished sum of $n$, but not of $n+1$, subcontinua.

It is well-known [1] that chainable continua are atriodic, hereditarily unicoherent, irreducible between two points, and that each subcontinuum is chainable also. For definitions of other terms see [7] and [8].

\section{Mutually aposyndetic products.}

Lemma 1. Suppose the semi-aposyndetic continuum $M$ is irreducible between two points. Then $M$ is an arc.

Proof. By [3, p. 116], $M$ is aposyndetic. But every aposyndetic irreducible continuum is an arc [11, p. 738].

Lemma 2. Suppose that

(1) $M$ is a chainable continuum of type $A^{\prime}$,

(2) $M$ is not semi-aposyndetic at $\{x, y\}$, 
(3) $T=K_{x} \cap K_{y}$,

(4) $q$ is a point of a continuum $N$,

(5) $H$ is a continuum in $M \times N$ containing the point $(x, q)$ in its interior, and

(6) $D$ denotes the $(x, q)$-component of $H \cap(T \times N)$. Then $\pi_{1}(D)=T . \quad\left(\pi_{j}\right.$ is the projection map onto the $j$ th factor space. $)$

Proof. By $[10$, p. 8], there is a minimal (with respect to refinement) monotone upper semi-continuous decomposition $\mathscr{D}$ of $M$ onto $[0,1]$. Let $f$ be the associated quotient map.

For each $z \in M, L_{z}$ is a continuum in $M[7$, p. 405]. Since $M$ is irreducible, each $K_{z}=L_{z}$ [3, p. 116]. Hence $T=L_{x} \cap L_{y}$, a continuum (by unicoherence). And by the definition of $K_{z}$ we have

(*) For each continuum $R$ containing either $x$ or $y$ in its interior, $T \subset R$.

Suppose the lemma fails. Let $s \in T-\pi_{1}(D)$. By [10, p. 25] there is a point $r \in[0,1]$ such that $T \subset f^{-1}(r)$. In order to prove (**) below, we temporarily assume that $0<r<1$. Let $A, B$, and $C$ denote the sets $f^{-1}([0, r)), f^{-1}((r, 1])$, and $f^{-1}(r)$ respectively. Since $C$ cannot have interior, $M=\mathrm{C} 1 A \cup \mathrm{C} 1 B$ (C1 denotes closure). Using this fact and (*), it can be shown that either $\mathrm{C} 1 A$ or $\mathrm{C} 1 B$ must contain all three of the points $x, y$, and $s$. We shall assume that $\{x, y, s\} \subset \mathrm{C} 1 A$. By $[10$, p. 10] $\mathscr{D} \cap \mathrm{C} 1 A$ is a monotone upper semi-continuous descomposition of $\mathrm{C} 1 A$ onto $[0,1]$, and it is easily seen to be minimal. By $[10$, p. 30] we have

(**) If $p \in A$ and $q, t \in C \cap \mathrm{C} 1 A$, then $t$ cuts $p$ from $q$ (in the continuum $\mathrm{C} 1 A$ ).

Note that $(* *)$ holds also in the case that $r$ is an end point of $[0,1]$, so that $(* *)$ holds for each $r \in[0,1]$.

If $C \cap \mathrm{C} 1 A \neq T$, then there is a point $c \in C \cap \mathrm{C} 1 A-T$, hence (by definition of $K_{x}$ and $K_{y}$ ) a subcontinuum $L \subset M-c$ containing $x$, say, in its interior. But then $L \cap \mathrm{C} 1 A$ is a subcontinuum (by unicoherence) of $\mathrm{C} 1 A$ which contains $x$ and $L^{0} \cap A$ but not the point $c$, contrary to (**). Thus $C \cap \mathrm{C} 1 A=T$.

For each $\varepsilon>0$ define $H_{\varepsilon}=H \cap\left[\mathrm{C} 1 f^{-1}((r-\varepsilon, r)) \times N\right]$. Suppose that for each $\varepsilon>0$ there is a continuum in $H_{\varepsilon}$ intersecting both $s \times N$ and $D$. The lim sup of such continua would then intersect both $s \times N$ and $D$, and would be contained in $T \times N$, hence in $D$ by the definition of $D$. Since this contradicts the choice of $s$, there must exist an $\varepsilon>0$ such that no continuum in $H_{\varepsilon}$ intersects both $s \times N$ and $D$. By [8, p. 15] there are closed disjoint sets $E_{s}$ and $E_{D}$ such that $H_{\varepsilon}=E_{s} \cup E_{D}$, $(s \times N) \cap H_{\varepsilon} \subset E_{s}$, and $D \subset E_{D}$. Let $z_{1}, z_{2}, \cdots$ be a sequence of points in $E_{D} \cap H^{0}-T \times N$ which converges to the point $(x, q)$. For each $i$, let $F_{i}=z_{i}$-component of $H \cap\left[f^{-1}((r-\varepsilon, r)) \times N\right]$. By [8, p. 18] each 
$F_{i}$ has a limit point (relative to $H$ ) in either $T \times N$ or in $f^{-1}(r-\varepsilon) \times$ $N$. If some $F_{j}$ has a limit point in $T \times N$, then $\mathrm{C} 1 F_{j}$ is a continuum in $E_{D}$ from $z_{j}$ to $T \times N$, whereupon its projection onto $M$ would contradict $\left({ }^{*}\right)$. Hence each $F_{i}$ has a limit point in $f^{-1}(r-\varepsilon) \times N$. Then $\lim \sup F_{i}$ is a continuum in $E_{D}$ from $f^{-1}(r-\varepsilon) \times N$ to $(x, q)$, whereupon its projection is a continuum in $\mathrm{C} 1 A$ containing $x$ and a point of $A$, but not containing $s$, contrary to $(* *)$.

Lemma 3. Suppose that

(1) $M$ is a chainable continuum containing an indecomposable subcontinuum $T$,

(2) $q$ is a point of a continuum $N$,

(3) $x$ is an inaccessible point of $T$,

(4) $H$ is a continuum in $M \times N$ containing $(x, q)$ in its interior, and

(5) $D$ denotes the $(x, q)$-component of $H \cap(T \times N)$. Then $\pi_{1}(D)=T$.

Proof. Assume that $T \neq M$; otherwise $\pi_{1}(D)=T$ clearly. Suppose $s \in T-\pi_{1}(D)$. For each $\varepsilon>0$ define $H_{\varepsilon}=H \cap\left[\mathrm{C} 1 N_{s}(T) \times N\right]$ where $N_{\varepsilon}(T)$ denotes the $\varepsilon$-neighborhood of $T$. As in the proof of Lemma 2, there exists an $\varepsilon>0$ and disjoint closed sets $E_{s}$ and $E_{D}$ such that $H_{\varepsilon}=E_{s} \cup E_{D},(s \times N) \cap H_{\varepsilon} \subset E_{s}$, and $D \subset E_{D}$. The closure of the $(x, q)$-component of $H \cap\left[N_{\varepsilon}(T) \times N\right]$ is then a continuum in $E_{D}$ from $(x, q)$ to the boundary of $N_{\varepsilon}(T) \times N$, whereupon its projection (onto $M$ ) is a subcontinuum of $M$ containing both $x$ and a point of $M-T$, but not $s$, contrary to the fact that $x$ is an inaccessible point of $T$.

Theorem 1. Let $M$ and $N$ be chainable continua. Then $M \times N$ is mutually aposyndetic if and only if $M=N=[0,1]$.

Proof. Clearly $[0,1]^{2}$ is mutually aposyndetic. To prove the other implication, we consider two cases.

Case $I$. At least one of $M$ and $N$ has an end point.

Suppose $q$ is an end point of $N$, and $M$ is not semi-aposyndetic. In order to define sets $D_{x}$ and $D_{y}$, we consider the following two cases:

Case 1. The continuum $M$ is of type $A^{\prime}$.

Let $x$ and $y$ be points of $M$ such that $M$ is not semi-aposyndetic at $\{x, y\}$, and let $T=K_{x} \cap K_{y}$. By mutual aposyndesis of $M \times N$, 
there are disjoint subcontinua $H_{x}$ and $H_{y}$ such that $(x, q) \in H_{x}^{0}$ and $(y, q) \in H_{y}^{0}$. Then for $z \in\{x, y\}$, let $D_{z}$ be the $(z, q)$-component of $H_{z} \cap$ $(T \times N)$, whereupon $\pi_{1}\left(D_{z}\right)=T$ by Lemma 2 .

Case 2. The continuum $M$ is not of type $A^{\prime}$.

By [10, p. 15], $M$ contains an indecomposable subcontinuum $T$ with interior. Suppose that $A, B$, and $C$ are disjoint subcontinua of $M$, each of which intersects $T$ but is not contained in $T$. Then $A \cup B \cup C \cup T$ is a triod, contrary to the fact that $M$ is chainable. Hence there are at most two composants of $T$ which intersect subcontinua like $A, B$, and $C$ above. Consequently, all the other composants of $T$ contain inaccessible points of $T$. Let $x$ and $y$ be distinct inaccessible points of $T$. By mutual aposyndesis, there are disjoint subcontinua $H_{x}$ and $H_{y}$ such that $(x, q) \in H_{x}^{0}$ and $(y, q) \in H_{y}^{0}$. Defining $D_{x}$ and $D_{y}$ as in Case 1, it follows from Lemma 3 that both $D_{x}$ and $D_{y}$ project onto $T$.

Choose $\varepsilon>0$ such that $D_{x}$ and $D_{y}$ are at least $2 \varepsilon$ apart. Let $f$ be an $\varepsilon$-map on $T$ and let $g$ be an $\varepsilon$-map on $N$ such that $g(q)=0$. Define the continuous function $h$ from $T \times N$ to $[0,1]^{2}$ by $h(a, b)=$ $\left((f(a), g(b))\right.$. Both $h(x, q)$ and $h(y, q)$ meet $[0,1] \times\{0\}$. Since both $D_{x}$ and $D_{y}$ project onto $T$, both continua $h\left(D_{x}\right)$ and $h\left(D_{y}\right)$ must intersect both $\{0\} \times[0,1]$ and $\{1\} \times[0,1]$. But by [8, p. 158], $h\left(D_{x}\right)$ and $h\left(D_{y}\right)$ must intersect, contradicting the choice of $\varepsilon$. Consequently, our assumption that $M$ was not semi-aposyndetic must be false. Then by Lemma $1, M$ is an arc, and hence has an end point. Now assume that $N$ is not semi-aposyndetic, and use the same argument (interchanging the roles of $M$ and $N$ ) to establish that $N$ also must be semi-aposyndetic, hence an arc.

\section{Case II. Neither $M$ nor $N$ has an end point.}

By $\left[4\right.$, p. 385], there are indecomposable terminal subcontinua $L_{M}$ and $L_{N}$ of $M$ and $N$ respectively. Let $q$ be an inaccessible point of $L_{N}$, and let $x$ and $y$ be distinct inaccessible points of $L_{M}$. By mutual aposyndesis, there are disjoint subcontinua $H_{x}$ and $H_{y}$ of $M \times N$ such that $(x, q) \in H_{x}^{0}$ and $(y, q) \in H_{y}^{0}$. Let $\varepsilon>0$ such that $H_{x}$ and $H_{y}$ are at least $2 \varepsilon$ apart. Let $f$ be an $\varepsilon$-map on $L_{M}$ and let $g$ be an $\varepsilon$-map on $N$ such that $g\left(L_{N}\right)=[0, c]$ for some $c \leqq 1$. Define $h: L_{M} \times N \rightarrow[0,1]^{2}$ by $h(a, b)=(f(a), g(b))$. For $z \in\{x, y\}$, let $D_{z}$ and $D_{z}^{\prime}$ denote the $(z, q)$ components of $H_{z} \cap\left(L_{M} \times N\right)$ and $H_{z} \cap\left(M \times L_{N}\right)$ respectively. By Lemma $3, \pi_{1}\left(D_{x}\right)=\pi_{1}\left(D_{y}\right)=L_{M}$ and $\pi_{2}\left(D_{x}^{\prime}\right)=\pi_{2}\left(D_{y}^{\prime}\right)=L_{N}$. By the choice of $\varepsilon, h\left(D_{x}\right) \cap h\left(D_{y}\right)=\varnothing$. Since $q$ is an inaccessible point of $L_{N}$, for each $z \in\{x, y\}$ either $\pi_{2}\left(D_{z}\right) \subset L_{N}$ or $L_{N} \subset \pi_{2}\left(D_{z}\right)$. 
Suppose that $L_{N} \subset \pi_{2}\left(D_{x}\right)$. Then $h\left(D_{x}\right)$ intersects both $[0,1] \times\{0\}$ and $[0,1] \times\{c\}$.

Case 1. $\pi_{2}\left(D_{y}\right) \subset L_{N}$.

Then $D_{y} \subset L_{M} \times L_{N}$. Let $B$ be a subcontinuum of $h\left(D_{x}\right)$ irreducible from $[0,1] \times\{0\}$ to $[0,1] \times\{c\}$. Since $\pi_{1}\left(D_{y}\right)=L_{M}, h\left(D_{y}\right)$ intersects both $\{0\} \times[0,1]$ and $\{1\} \times[0,1]$. By [8, p. 158], the continua $B$ and $h\left(D_{y}\right)$ must intersect, contrary to the fact that $h\left(D_{x}\right) \cap h\left(D_{y}\right)=\varnothing$.

Case 2. $L_{N} \subset \pi_{2}\left(D_{y}\right)$.

For $z \in\{x, y\}$, let $d_{z}$ denote the maximum of the numbers $b \in[0,1]$ such that the point $(0, b) \in h\left(D_{z}\right)$. If $d_{x}>d_{y}$, then $h\left(D_{x}\right)$ intersects both $[0,1] \times\{0\}$ and the point $\left(0, d_{x}\right)$, and $h\left(D_{y}\right)$ intersects both $\{0\} \times$ $[0,1]$ and $\{1\} \times[0,1]$. Hence $h\left(D_{x}\right)$ and $h\left(D_{y}\right)$ must intersect [8, p. 158]. A similar contradiction is reached in case $d_{y}>d_{x}$.

Since the supposition that $L_{N} \subset \pi_{2}\left(D_{x}\right)$ results in a contradiction, we have that $\pi_{2}\left(D_{x}\right) \subset L_{N}$.

In a similar manner (by interchanging the roles of $L_{M}$ and $L_{N}$, and of $D_{x}$ and $D_{y}^{\prime}$, and making the other obvious modifications) it can be shown that $\pi_{1}\left(D_{y}^{\prime}\right) \subset L_{M}$. Hence both $D_{x}$ and $D_{y}^{\prime}$ are contained in $L_{M} \times L_{N}$. Let $g^{\prime}$ be an $\varepsilon$-map on $L_{N}$, and define $h^{\prime}: L_{M} \times L_{N} \rightarrow[0,1]^{2}$ by $h^{\prime}(a, b)=\left(f(a), g^{\prime}(b)\right)$. By the choice of $\varepsilon, h^{\prime}\left(D_{x}\right) \cap h^{\prime}\left(D_{y}^{\prime}\right)=\varnothing$. But since $h^{\prime}\left(D_{x}\right)$ intersects both $\{0\} \times[0,1]$ and $\{1\} \times[0,1]$, and since $h^{\prime}\left(D_{y}^{\prime}\right)$ intersects both $[0,1] \times\{0\}$ and $[0,1] \times\{1\}$, the continua $h^{\prime}\left(D_{x}\right)$ and $h^{\prime}\left(D_{y}^{\prime}\right)$ must intersect [8, p. 158]. This contradiction concludes Case II, and hence the proof of the theorem.

The chainability requirement in the hypothesis of Theorem 1 cannot be replaced by the the requirement that the continua be of type $A^{\prime}$ :

ExAMPle. A nonchainable planar continuum $M$ of type $A^{\prime}$ such that $M^{2}$ is mutually aposyndetic. Let $M$ be the union of two disjoint circles plus an open ray (copy of $(0,1)$ ) which spirals down on one circle at one end and on the other circle at the other end. The minimal decomposition of $M$ would have only the two circles as nondegenerate elements. Since $M$ contains a circle, it is clearly not chainable. However, it can be shown that $M^{2}$ is mutually aposyndetic.

4. Strict non- $n$-mutual aposyndesis. Hagopian has shown [5, p. 621] that the product of two chainable continua is strictly nonmutually aposyndetic if and only if each of the two continua is in- 
decomposable. [Hagopian actually showed it for the case when the two factors are the same continuum; however it is clear that with slight modifications his proof will prove this more general result.] One direction of implication generalizes easily to $n$-mutual aposyndesis:

Theorem 2. Let $n \geqq 2$. Suppose $M_{1}$ and $M_{2}$ are continua, and $M_{1} \times M_{2}$ is strictly non-n-mutually aposyndetic. Then for each $i$ $(i=1,2), M_{i}$ is $r_{i}$-indecomposable for some integer $r_{i}<n$.

Proof. Suppose $M_{1}$ is the finished sum of $n$ subcontinua $A_{1}, \cdots, A_{n}$. Then for each $j \leqq n$ there is a point $p_{j} \in A_{j}-\mathrm{U}_{i \neq j} A_{i}$. In $M_{2}$ let $U_{1}, \cdots, U_{n}$ be open sets with disjoint closures. Then for each $j \leqq n$, let $H_{j}=\left(A_{j} \times \mathrm{C} 1 U_{j}\right) \cup\left(p_{j} \times M_{2}\right)$, clearly a continuum with interior. Since the $H_{j}$ 's are disjoint, $M_{1} \times M_{2}$ is not strictly non- $n$-mutually aposyndetic. This contradiction implies that $M_{1}$ is the finished sum of at most $n-1$ subcontinua, and the proof is complete.

The other direction of implication in Hagopian's result is represented by

(***) Suppose $M$ is an $m$-indecomposable chainable continuum and $N$ is an $n$-indecomposable chainable continuum. Then $M \times N$ is strictly non- $(m n+1)$-mutually aposyndetic.

Question. Is $(* * *)$ true for all values of $m$ and $n$ ?

By the above remarks, $(* * *)$ holds for $m=n=1$. The next theorem shows that $m=2$ and $n=1$ are also values for which $\left({ }^{* *}\right)$ is true.

THeorem 3. Suppose that $M_{1}$ and $M_{2}$ are chainable continua, and $M_{2}$ is indecomposable. Then $M_{1} \times M_{2}$ is strictly non-3-mutually aposyndetic if and only if $M_{1}$ is either indecomposable or 2-indecomposable.

Proof. If $M_{1} \times M_{2}$ is strictly non-3-mutually aposyndetic, then the conclusion follows from Theorem 2.

Conversely, suppose that $M_{1}$ is either indecomposable or 2-indecomposable. In case $M_{1}$ is indecomposable, then $M_{1} \times M_{2}$ is strictly nonmutually aposyndetic, hence strictly non-3-mutually aposyndetic. So we assume that $M_{1}$ is 2-indecomposable.

Suppose that there are three disjoint continua $H_{1}, H_{2}$, and $H_{3}$ with interior in $M_{1} \times M_{2}$. By [9, p. 649], $M_{1}=A \cup B$ where $A$ and $B$ are proper indecomposable subcontinua. One of $A \times M_{2}$ and $B \times M_{2}$ (say $A \times M_{2}$ ) must contain interior points of at least two of the three $H_{i}$ 's (say $H_{1}$ and $H_{2}$ ). Since $M_{2}$ is indecomposable, $\pi_{2}\left(H_{1}\right)=\pi_{2}\left(H_{2}\right)=M_{2}$. Similarly for $i=1,2, \pi_{1}\left(H_{i}\right) \supset A$; otherwise $\pi_{1}\left(H_{i}\right) \cap A$ would be a pro- 
per subcontinuum of $A$ with interior, contrary to the fact that $A$ is indecomposable.

Let $\varepsilon>0$ such that $H_{1}$ is of distance at least $2 \varepsilon$ from $H_{2}$. Let $g$ be an $\varepsilon$-map on $M_{2}$ and let $f$ be an $\varepsilon$-map on $M_{1}$ such that $f(A)$ is an initial segment of $[0,1]$. Define the continuous function $h$ from $M_{1} \times M_{2}$ to $[0,1]^{2}$ by $h(x, y)=(f(x), g(y))$. By the choice of $\varepsilon$, the continua $h\left(H_{1}\right)$ and $h\left(H_{2}\right)$ are disjoint. For $i=1,2, h\left(H_{i}\right)$ meets both $y=0$ and $y=1$ since $\pi_{2}\left(H_{i}\right)=M_{2}$. And for $i=1,2$, since $\pi_{1}\left(H_{i}\right) \supset A$, $h\left(H_{i}\right)$ projects onto $f(A)$. Let $a_{1}$ be the left-most point (i.e., smallest first coordinate) of $h\left(H_{1}\right)$ on the top edge $(y=1)$, and let $a_{2}$ be the corresponding point for $H_{2}$. We shall assume, without loss of generality, that $a_{1}$ lies to the left of $a_{2}$. Since $h\left(H_{1}\right)$ intersects $y=0$ and $h\left(H_{2}\right)$ intersects $x=0$, the continua $h\left(H_{1}\right)$ and $h\left(H_{2}\right)$ must intersect [8, p. 158]. This contradiction concludes the proof.

Question. For what values of $m$ and $n$ does (***) hold without the requirement that $M$ and $N$ be chainable [cf. 5, p. 622]?

\section{REFERENCES}

1. R. H. Bing, Snake-like continua, Duke Math. J., 18 (1951), 653-663.

2. C. E. Burgess, Separation properties and n-indecomposable continua, Duke Math. J., 24 (1956), 595-600.

3. H. S. Davis, D. P. Stadtlander, and P. M. Swingle, Properties of the set function $T_{n}$, Portugaliae Mathematica, 21 (1962), 113-133.

4. J. B. Fugate, A characterization of chainable continua, Canadian J. Math., 21 (1969), 383-393.

5. C. L. Hagopian, Mutual aposyndesis, Proc. Amer. Math. Soc., 23 (1969), 615-622.

6. F. B. Jones, Aposyndetic continua and certain boundary problems, Amer. J. Math., 63 (1941), 545-553.

7. - Concerning non-aposyndetic continua, Amer. J. Math., 70 (1948), 403-413.

8. R. L. Moore, Foundations of Point Set Theory, Rev. ed., Amer. Math. Soc. Colloq. Publ., vol. 13, Amer. Math. Soc., Providence, R.I., 1962.

9. P. M. Swingle, Generalized indecomposable continua, Amer. J. Math., 52 (1930), $647-658$.

10. E. S. Thomas, Jr., Monotone decompositions of irreducible continua, Rozprawy Matematyczne, 50 (1966), 1-74.

11. G. T. Whyburn. Semi-locally-connected sets, Amer. J. Math., 61 (1939), 733-749.

Received July 9, 1970 and in revised form September 22, 1970. This paper represents part of the author's doctoral dissertation under the direction of Professor F. Burton Jones. This work was supported by a NASA Graduate Fellowship.

University of CAlifornia, Riverside

AND

UNIVERSITY OF WYOMING 


\title{
PACIFIC JOURNAL OF MATHEMATICS
}

\author{
EDITORS
}

\author{
H. SAMelson \\ Stanford University \\ Stanford, California 94305 \\ C. R. HoBBy \\ University of Washington \\ Seattle, Washington 98105
}

J. DugunduI

Department of Mathematics

University of Southern California

Los Angeles, California 90007

RICHARD ARENS

University of California

Los Angeles, California 90024

\section{ASSOCIATE EDITORS}

\author{
E. F. BeCKENBACH
}

B. H. NEUMANN

F. WoLF

K. YOSHIDA

\section{SUPPORTING INSTITUTIONS}

\author{
UNIVERSITY OF BRITISH COLUMBIA \\ CALIFORNIA INSTITUTE OF TECHNOLOGY \\ UNIVERSITY OF CALIFORNIA \\ MONTANA STATE UNIVERSITY \\ UNIVERSITY OF NEVADA \\ NEW MEXICO STATE UNIVERSITY \\ OREGON STATE UNIVERSITY \\ UNIVERSITY OF OREGON \\ OSAKA UNIVERSITY \\ UNIVERSITY OF SOUTHERN CALIFORNIA
}

\author{
STANFORD UNIVERSITY \\ UNIVERSITY OF TOKYO \\ UNIVERSITY OF UTAH \\ WASHINGTON STATE UNIVERSITY \\ UNIVERSITY OF WASHINGTON \\ AMERICAN MATHEMATICAL SOCIETY \\ CHEVRON RESEARCH CORPORATION \\ NAVAL WEAPONS CENTER
}

The Supporting Institutions listed above contribute to the cost of publication of this Journal, but they are not owners or publishers and have no responsibility for its content or policies.

Mathematical papers intended for publication in the Pacific Journal of Mathematics should be in typed form or offset-reproduced, (not dittoed), double spaced with large margins. Underline Greek letters in red, German in green, and script in blue. The first paragraph or two must be capable of being used separately as a synopsis of the entire paper. The editorial "we" must not be used in the synopsis, and items of the bibliography should not be cited there unless absolutely necessary, in which case they must be identified by author and Journal, rather than by item number. Manuscripts, in duplicate if possible, may be sent to any one of the four editors. Please classify according to the scheme of Math. Rev. Index to Vol. 39. All other communications to the editors should be addressed to the managing editor, Richard Arens, University of California, Los Angeles, California, 90024.

50 reprints are provided free for each article; additional copies may be obtained at cost in multiples of 50 .

The Pacific Journal of Mathematics is published monthly. Effective with Volume 16 the price per volume (3 numbers) is $\$ 8.00$; single issues, $\$ 3.00$. Special price for current issues to individual faculty members of supporting institutions and to individual members of the American Mathematical Society: $\$ 4.00$ per volume; single issues $\$ 1.50$. Back numbers are available.

Subscriptions, orders for back numbers, and changes of address should be sent to Pacific Journal of Mathematics, 103 Highland Boulevard, Berkeley, California, 94708.

PUBLISHED BY PACIFIC JOURNAL OF MATHEMATICS, A NON-PROFIT CORPORATION

Printed at Kokusai Bunken Insatsusha (International Academic Printing Co., Ltd.), 7-17, Fujimi 2-chome, Chiyoda-ku, Tokyo, Japan. 


\section{Pacific Journal of Mathematics}

\section{Vol. 37, No. $3 \quad$ March, 1971}

Mohammad Shafqat Ali and Marvin David Marcus, On the degree of the

minimal polynomial of a commutator operator ................ 561

Howard Anton and William J. Pervin, Integration on topological

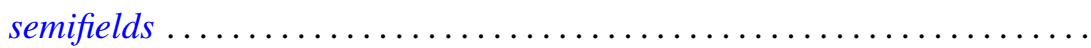

Martin Bartelt, Multipliers and operator algebras on bounded analytic

functions .................................... 575

Donald Earl Bennett, Aposyndetic properties of unicoherent continua ...... 585

James W. Bond, Lie algebras of genus one and genus two ............. 591

Mario Borelli, The cohomology of divisorial varieties ............... 617

Carlos R. Borges, How to recognize homeomorphisms and isometries ....... 625

J. C. Breckenridge, Burkill-Cesari integrals of quasi additive interval

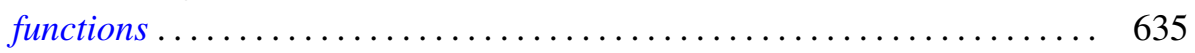

J. Csima, A class of counterexamples on permanents ................ 655

Carl Hanson Fitzgerald, Conformal mappings onto $\omega$-swirly domains . . . . . . 657

Newcomb Greenleaf, Analytic sheaves on Klein surfaces .............. 671

G. Goss and Giovanni Viglino, C-compact and functionally compact

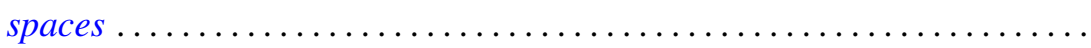

Charles Lemuel Hagopian, Arcwise connectivity of semi-aposyndetic plane

continua ..................................... 683

John Harris and Olga Higgins, Prime generators with parabolic limits ...

David Michael Henry, Stratifiable spaces, semi-stratifiable spaces, and their

relation through mappings .......................

Raymond D. Holmes, On contractive semigroups of mappings ........... 701

Joseph Edmund Kist and P. H. Maserick, BV-functions on semilattices ....... 711

Shûichirô Maeda, On point-free parallelism and Wilcox lattices ........... 725

Gary L. Musser, Linear semiprime $(p ; q)$ radicals ................. 749

William Charles Nemitz and Thomas Paul Whaley, Varieties of implicative

semilattices..................................... 759

Jaroslav Nešetřil, A congruence theorem for asymmetric trees ............ 771

Robert Anthony Nowlan, A study of $H$-spaces via left translations .......... 779

Gert Kjærgaard Pedersen, Atomic and diffuse functionals on a $C^{*}$-algebra ... 795

Tilak Raj Prabhakar, On the other set of the biorthogonal polynomials

suggested by the Laguerre polynomials...

801

Leland Edward Rogers, Mutually aposyndetic products of chainable

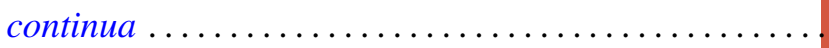

Frederick Stern, An estimate for Wiener integrals connected with squared

error in a Fourier series approximation.

Leonard Paul Sternbach, On k-shrinking and k-boundedly complete basic

sequences and quasi-reflexive spaces .................... 817

Pak-Ken Wong, Modular annihilator $A^{*}$-algebras ........ 